\title{
Investigation of per- and polyfluoroalkyl substances (PFAS) in soils and sewage sludges by fluorine K-edge XANES spectroscopy and combustion ion chromatography
}

\author{
Philipp Roesch $^{1} \cdot$ Christian Vogel $^{1}$ (1) $\cdot$ Thomas Huthwelker $^{2} \cdot$ Philipp Wittwer $^{1} \cdot$ Franz-Georg Simon $^{1}$
}

Received: 10 September 2021 / Accepted: 24 November 2021 / Published online: 3 December 2021

(c) The Author(s) 2021

\begin{abstract}
For the first time, fluorine K-edge X-ray absorption near-edge structure (XANES) spectroscopy was applied to detect perand polyfluoroalkyl substances (PFAS) in various soil and sewage sludge samples. The method can be used to determine the speciation of inorganic and organic fluorides, without pre-treatment of solid samples. Therefore, XANES spectra of several inorganic fluorides as well as selected fluorinated organic compounds were recorded. While inorganic fluorides partially exhibit a variety of sharp spectral features in the XANES spectrum, almost all inspected organofluorine compounds show two distinct broad features at 688.5 and $692.0 \mathrm{eV}$. Moreover, the peak intensity ratio $688.5 \mathrm{eV} / 692.0 \mathrm{eV}$ in the PFAS XANES spectrum can be inversely correlated to the chain length of the perfluoro sulfonic acid group. The detection of targeted PFAS by bulk-XANES spectroscopy in combination with linear combination fitting in soils and sewage sludges was not applicable due to the low organic fluorine to total fluorine ratio of the samples $(0.01-1.84 \%)$. Nonetheless, direct analysis of pure PFAS revealed that analysis of organofluorine species might be achieved in higher concentrated samples. Furthermore, quantitative measurements by combustion ion chromatography (CIC) evaluated as sum parameters extractable organically bound fluorine (EOF) and total fluorine (TF) emphasize that besides soils, sewage sludges are a significant source of organic fluorine in agriculture $(154-7209 \mu \mathrm{g} / \mathrm{kg})$.
\end{abstract}

Keywords X-ray absorption near-edge structure (XANES) spectroscopy · Extractable organically bound fluorine (EOF) . Total fluorine (TF) · Sum parameter analysis · Persistent organic pollutants (POPs)

Responsible Editor: Kitae Baek

Philipp Roesch and Christian Vogel contributed equally to this work.

Philipp Roesch

philipp.roesch@bam.de

$\triangle$ Christian Vogel

christian.vogel@bam.de

1 Bundesanstalt für Materialforschung und -prüfung (BAM), Division 4.3 Contaminant Transfer and Environmental Technologies, Unter den Eichen 87, 12205 Berlin, Germany

2 Paul Scherrer Institute, Swiss Light Source, 5232 Villigen PSI, Switzerland

\section{Introduction}

Per- and polyfluoroalkyl substances (PFAS) have emerged over the course of the last 20 years as a global pollution issue (Giesy and Kannan 2001; Lindstrom et al. 2011; De Silva et al. 2021). Originally designed and produced as substantially effective lipophobic and hydrophobic surface coatings and additives for industrial purposes (Kissa 2001), PFAS quickly found use in numerous consumer applications like cosmetics (Schultes et al. 2018), fast-food packaging (Schaider et al. 2017; Schultes et al. 2019), coatings on cooking ware or outdoor clothing (Hill et al. 2017; Schellenberger et al. 2019; Glüge et al. 2020). Over the last decades, increasing production, consumption, and disposal has led to wider distribution of PFAS in the environment (Stoiber et al. 2020; Jacob et al. 2021), and numerous cases of contaminated sites were reported worldwide (Sunderland et al. 2019; Kotthoff et al. 2020). A major environmental impact can be traced back to the ubiquitous use of PFAS 
mixtures as highly effective aqueous film forming foams (AFFFs) (Leeson et al. 2021), predominantly on firefighting training grounds (Kärrman et al. 2011; Baduel et al. 2015; Mumtaz et al. 2019; Nickerson et al. 2020). Altogether, there are currently more than 4700 known and partly characterized fluorinated compounds identified by the Organisation for Economic Co-operation and Development (OECD), most of them classified as toxic or dangerous for the environment (OECD 2018).

Due to their highly stable C-F bond $\left(D_{0}=485 \mathrm{~kJ} / \mathrm{mol}\right)$, most PFAS exhibit a chemically inert character, making them difficult for microorganisms to degrade and inaccessible for classical environmental degradation processes like oxidation (Liu and Mejia Avendano 2013; Roesch et al. 2020). The persistence and toxicity of especially $C_{8}-C_{14}$ per- and polyfluorinated carboxylic and sulfonic acids and their respective salts lead to their inclusion to the list of regulated substances within the EU (Lallas 2017). Since addition to the group of banned persistent organic pollutants (POP) at the Stockholm Convention in 2009 and 2020, perfluorooctanesulfonic acid (PFOS), perfluorooctanoic acid (PFOA), and other long-chained molecules are often referred to as "legacy PFAS" (Sun et al. 2016). As a consequence, manufacturers moved to the production of short-chain $\left(\mathrm{C}_{4}-\mathrm{C}_{7}\right)$ and ultrashort-chain $\left(\mathrm{C}_{1}-\mathrm{C}_{3}\right)$ PFAS (Ateia et al. 2019) and differently fluorinated derivatives like GenX $\left(\mathrm{C}_{3} \mathrm{~F}_{7} \mathrm{OCF}\left(\mathrm{CF}_{3}\right) \mathrm{COONH}_{4}\right)$ and ADONA $\left(\mathrm{C}_{7} \mathrm{H}_{5} \mathrm{~F}_{12} \mathrm{NO}_{4}\right)$ for commercial production and application (Lindstrom et al. 2011). In many cases, PFAS substitutes of shorter chain length exhibit similar chemical and physical properties as their longer homologues, but even less is known regarding their biocompatibility, toxicity, and persistence. The ongoing production of new, yet unrestricted, PFAS alternatives has become a major challenge not only for researchers across the planet, but also for environmental routine analytics, since the state-of-the-art method LC-MS/MS relies on structural information and availability of isotope standards of the targeted compound (Nakayama et al. 2019). Although establishment of the total oxidizable precursor (TOP) assay protocol significantly improves their analytical range (Houtz and Sedlak 2012; Janda et al. 2019), target analytical methods only enable detection of approximately 70 different PFAS, thus will increasingly become a limiting factor (Koch et al. 2020). Since the number of PFAS alternatives is also relative to advancing progress of the regulatory enforcement, different future analytical approaches are inevitable. First reported by Miyake et al. in 2007 (Miyake et al. 2007), fluorine sum parameters like adsorbable organic fluorine (AOF), extractable organic fluorine (EOF), and total fluorine (TF) can be applied to survey and detect the presence of large amounts of unidentified organofluorine compounds in environmental matrices like water sources (Wagner et al. 2013; Willach et al. 2016; von Abercron et al. 2019;
Gehrenkemper et al. 2021), biota (Koch et al. 2019; Spaan et al. 2020; Wang et al. 2020), or soils (Wang et al. 2013; Yeung et al. 2013; Tan et al. 2014), yielding a much more comprehensive image. More than a decade later, fluorine sum parameters have been established as a useful supplement to classic target analytical approaches of PFAS (Nakayama et al. 2019) and were implemented for the first time as a sum value "PFAS-total" in the recently revised Drinking Water Directive (2020/2184) by the European Commission.

In contrast, X-ray absorption near-edge structure (XANES) spectroscopy has been widely applied to identify low concentration of element-specific contamination without pretreatment in environmental samples in the past (Vogel et al. 2016). However, until today, only a small number of fluorine K-edge XANES spectra of metal fluorides were published (Oizumi et al. 1985; Nakai et al. 1986; Hudson et al. 1994; Schroeder and Weiher 2006; Murugesan et al. 2019). The XANES approach enables a penetration depth of approx. $1 \mu \mathrm{m}$ (at fluorine K-edge energy; depending on the matrix) which is significantly deeper than for X-ray photoelectron spectroscopy (XPS; penetration depth approx. $10 \mathrm{~nm}$ ) (Tokranov et al. 2019). To the best of our knowledge, only one single fluorine XANES spectrum of perfluorooctanoic acid (PFOA) was published so far (Yan et al. 2021). Thus, the aims of this study were to analyze various PFAS and fluorinated organic compounds by fluorine XANES spectroscopy and to identify PFAS contamination directly in soils and sewage sludges upon application of fluorine XANES spectroscopy without pre-treatment of the samples. Therefore, bulk-XANES spectra of various PFAS, soils, and sewage sludges were collected and analyzed with regard to the findings of the PFAS sum parameter analysis TF/EOF.

\section{Materials and methods}

\section{Sampling}

Four different soil samples from remediation activities in Germany and six additional sewage sludge samples from various wastewater treatment plants in Germany were analyzed. The crude samples were air-dried at room temperature for 30 days and homogenized afterwards. More detailed treatment and investigation data of all soil samples are summarized in the SI (see also Table S1).

\section{Chemicals and reagents}

The following chemicals and materials were used for the experimental work: sodium trifluoromethyl sulfonate (NaTFMS, 98\%, BLD pharma), potassium perfluorobutyl sulfonate (K-PFBS, 98\%, Sigma Aldrich), potassium perfluorhexyl sulfonate (K-PFHxS, $\geq 98 \%$, Sigma Aldrich), 
perfluorooctanesulfonic acid (PFOS, 97\%, abcr), sodium trifluoroacetate (Na-TFA, 98\%, Alfa Aesar), perfluorooctanoic acid (PFOA, 96\%, Sigma Aldrich), perfluorooctanesulfonic acid (PFOS, 97\%, abcr), perfluoro-2-propoxypropanoic acid (HFPO-DA, 97\%, abcr; carbonic acid of "GenX"), perfluoropentadecane (PFPD, 97\%, Fluorochem), 1H,1H,2H,2H-perfluorooctanephosphonic acid (PFOPA, 95\%, Sigma Aldrich), 8:2 fluorotelomer alcohol (8:2-FTOH, 97\%, Sigma Aldrich), 4-fluorobenzoic acid (4-FBA, 99\%, J\&K), fluoxetine $\cdot \mathrm{HCl}$ ( $N$-methyl- $\gamma$-[4-(trifluoromethyl)phenoxy]benzenepropanamine, $>98 \%$, Fluorochem), tolylfluanid (1,1-dichloro- $N$ [(dimethylamino)sulfonyl]-1-fluoro- $N$-(4-methylphenyl) methanesulfenamide, Pestanal, analytical standard, Sigma Aldrich), perfluoroalkoxy alkanes polymer (PFA, PFA hose, Thermo Scientific), polytetrafluoroethylene (PTFE; Teflon tape Ulith "FRp"), $\mathrm{AlF}_{3} \cdot 3 \mathrm{H}_{2} \mathrm{O}(\geq 97 \%$, Roth chemicals), $\mathrm{CaF}_{2}$ (99.5\%, Alfa Aesar), $\mathrm{FeF}_{3} \cdot 3 \mathrm{H}_{2} \mathrm{O}$ (Fluorochem), $\mathrm{MgF}_{2}$ (99\%, 200 mesh, Alfa Aesar), $\mathrm{Na}_{2} \mathrm{SiF}_{6}$ (99\%, abcr), $\mathrm{GaF}_{3} \cdot 3 \mathrm{H}_{2} \mathrm{O}$ (99.5\%, abcr), $\mathrm{NaF}$ (p.a., Merck KGaA), KF (>99\%, Roth Chemicals), $\mathrm{NH}_{4} \mathrm{~F}$ (p.a., Supelco®, Merck $\mathrm{KGaA})$, and $\mathrm{SnF}_{2}(99 \%$, Sigma Aldrich). Fluoroapatite (FAp) was precipitated from a $\mathrm{NH}_{4} \mathrm{H}_{2} \mathrm{PO}_{4}$ (p.a., J.T. Baker) solution with $\mathrm{NH}_{4} \mathrm{~F}$ and $\mathrm{Ca}\left(\mathrm{NO}_{3}\right)_{2} \bullet 4 \mathrm{H}_{2} \mathrm{O}$ (both p.a., Sigma Aldrich) and structurally verified by XRD (Gross et al. 2001). For the extraction process, $\mathrm{NH}_{3}\left(25 \%\right.$, Suprapur ${ }^{\circledR}$, Merck KGaA), HCOOH (99-100\%, Chemsolute), methanol (MeOH; 99.98\%, Rotisolv® HPLC grade, Roth Chemicals), $n$-hexane (Suprasolv, Supelco), acetone $(99.5 \%$, p.a., Chemsolute), and $\mathrm{WO}_{3}(99.9 \%$, Merck KGaA) were used. A Labostar DI 2 system (Siemens Evoqua Water Technologies $\mathrm{GmbH})$ generating ultrapure water $(<0.6 \mu \mathrm{S} / \mathrm{cm})$ was used for all applications and combustion ion chromatography (CIC) experiments. All utilized SPE cartridges were preassembled Strata PFAS containing a weakly ion exchange (WAX) resin/graphitized carbon black (GCB) combination, purchased by Phenomenex Ltd., Germany.

\section{Fluorine K-edge XANES spectroscopy}

Fluorine K-edge XANES spectra were collected on the PHOENIX II beamline of the Swiss Light Source (SLS, Villigen, Switzerland). All soil and sludge samples were pressed into small pellets for easier sample preparation prior to the measurements, and the experiments were conducted at room temperature under a high vacuum $\left(10^{-6} \mathrm{mbar}\right)$. The fluorine references were prepared as a thin layer of a few $\mathrm{mg}$ spread on a F-free carbon tape. The incoming intensity $\left(I_{0}\right)$ was measured from the total electron yield signal taken from a nickel-coated, 0.5-mm-thick polyester foil. Bulk-XANES spectra were collected from an area of approx. $2 \times 3 \mathrm{~mm}$ at the sample over the range $660-780 \mathrm{eV}$ in fluorescence mode, using a silicon drift diode (SDD, manufacturer: Ketek). The collected spectra were normalized and background corrected using the Athena software from the Demeter 0.9.26 package (Ravel and Newville 2005). Furthermore, the F K-edge bulk-XANES spectra of the samples were analyzed with linear combination (LC) fitting (Calvin and Furst 2013) of the $\mathrm{F}$ reference compounds with the Demeter Athena software. Therefore, processed data of the following $\mathrm{F}$ K-edge XANES spectra were used: $\mathrm{CaF}_{2}, \mathrm{MgF}_{2}, \mathrm{Na}_{2} \mathrm{SiF}_{6}$, $\mathrm{FeF}_{3} \cdot 3 \mathrm{H}_{2} \mathrm{O}, \mathrm{AlF}_{3} \cdot 3 \mathrm{H}_{2} \mathrm{O}, \mathrm{FAp}, \mathrm{NaF}, \mathrm{PFOS}, \mathrm{Na}-\mathrm{TFMS}, \mathrm{Na}-$ TFA, fluoxetine, tolylfluanid, and HFPO-DA. The spectral range was set from -9 to $+15 \mathrm{eV}$ of the fluorine K-edge. The maximum number of compounds in the final LC fit was limited to three, and the sum of the compounds was forced to add up to $100 \%$. From the resulting LC fits, the ones with the lowest goodness of fit $R$-values were chosen.

\section{Sample extraction and preparation for quantitative analysis}

For determination of sum parameter EOF, all samples (soils and sludges) were extracted and prepared according to an optimized method based on previous work by Wilhelm et al. (2019). To assure reproducibility, all samples were prepared in triplicates. Dried solid samples (sludge: $1 \mathrm{~g}$, soil: $2 \mathrm{~g}$ ) were weighed directly in $50 \mathrm{ml}$ centrifugal polypropylene (PP) tubes, followed by addition of $10 \mathrm{ml}$ of a $\mathrm{NH}_{3}$ in $\mathrm{MeOH}$ $(0.1 \mathrm{M})$ solution. After that, a standardized extraction process including sonication (15 $\mathrm{min}$ ), followed by $30 \mathrm{~min}$ of vortexing $\left(1500 \mathrm{~min}^{-1}\right)$ and subsequent centrifugation (5 min, $4000 \mathrm{~min}^{-1}$ ), was applied to the samples. Following up, the supernatant liquid was carefully decanted to a fresh $50 \mathrm{~mL}$ PP tube to avoid transfer of solids from the extraction process. The remaining residues subsequently were extracted in a second run using $10 \mathrm{ml}$ of pure $\mathrm{MeOH}$, followed by the aforementioned extraction process. After decanting the eluates, the combined solutions were carefully concentrated ( $\sim 2 \mathrm{ml}$ ) using a gentle constant flow of $\mathrm{N}_{2}$. For SPE preparation, all samples were $\mathrm{pH}$ adjusted $(\mathrm{pH}=4-5)$ using $0.5 \%$ formic acid, diluted to $15 \mathrm{ml}$ with ultrapure water, and eventually centrifuged.

All SPE cartridges were primed applying first $4 \mathrm{ml}$ basic $\mathrm{MeOH}\left(0.3 \% \mathrm{NH}_{3}\right)$, then $4 \mathrm{ml}$ pure $\mathrm{MeOH}$, followed by two subsequent $4 \mathrm{ml}$ steps of ultrapure water. After that, diluted samples were loaded on the solid phases maintaining a constant dripping rate of approx. 1 drop/s. Two washing steps were applied in the following, using $2 \times 10 \mathrm{ml}$ of aqueous ammonia solution $(0.01 \%)$ and $10 \mathrm{ml}$ of deionized water. Subsequent application of a constant vacuum ( $40 \mathrm{mbar}$ ) for approx. 30 min leads to cautious drying of the loaded SPE cartridges. After that, all cartridges were firstly eluted upon slow addition of $2 \times 2 \mathrm{ml}$ pure $\mathrm{MeOH}$, followed by threetime addition of $2 \mathrm{ml}$ basic $\mathrm{MeOH}\left(0.3 \% \mathrm{NH}_{3}\right)$ into $15 \mathrm{ml} \mathrm{PP}$ vials. Eventually, all SPE cartridges were eluted with $4 \mathrm{ml}$ hexanes, followed by $4 \mathrm{ml}$ of acetone, and collected in fresh 
$15 \mathrm{ml}$ PP vials. The separated eluates were slowly evaporated to dryness by $\mathrm{N}_{2}$ gas and subsequently reconstituted in $2 \mathrm{~mL}$ of fresh $\mathrm{MeOH}$.

\section{Sum parameter analysis (TF/EOF)}

All soil and sewage sludge samples were quantified by CIC similar to previously reported work (Gehrenkemper et al. 2021). For TF analysis, pre-homogenized solid samples $(40 \mathrm{mg}$ ) were weighed directly into ceramic boats and subsequently analyzed by CIC. Prior to analysis, a four-fold excess of powdered $\mathrm{WO}_{3}$, serving as flux for high-melting inorganic fluorides, was added to the sample boats. For extractable organically bound fluorine (EOF) analysis, methanol extracts of all samples $(500 \mu \mathrm{L})$ were injected on quartz wool-filled ceramic boats before being measured by CIC. All liquid samples were handled using a mechanical pipet (Transferpette, Brand $\mathrm{GmbH}+\mathrm{CO} \mathrm{KG}$ ). All TF and EOF samples were measured in triplicates to maintain quality in data consistency. In order to quantify the correct absorption volume, an internal standard of known concentration was added to the absorption solution before each combustion step. Quantification of the samples was enabled using an eleven-point calibration curve from 1 to $20 \mu \mathrm{g} / \mathrm{L} \mathrm{F}^{-}\left(R^{2}=0.995\right)$ for low fluoride-containing samples and a six-point curve from 10 to $500 \mu \mathrm{g} / \mathrm{L} \mathrm{F}^{-}\left(R^{2}=0.999\right)$ for higher fluoride value detection. Moreover, a ten-point calibration curve from 1 to $1000 \mathrm{mg} / \mathrm{L}$ $\mathrm{F}^{-}\left(R^{2}=0.997\right)$ was prepared for all TF measurements. More detailed description on CIC data acquisition and quality control, including method detection (LOD) and quantification limit (LOQ), are provided in the SI.

\section{Results and discussion}

\section{Analysis of inorganic fluorides and organofluorine compounds by fluorine K-edge bulk-XANES spectroscopy}

Figures 1 and 2 show the normalized F K-edge XANES spectra of various inorganic and organic fluorine compounds.

While the inorganic fluorine compounds partially have a variety of differently sharp spectral features, the organic fluorine compounds show only two major features. The spectrum of $\mathrm{NaF}$ shows a little pre-peak at 686.3, a broad whiteline between 688.0 and $693.0 \mathrm{eV}$, and several smaller features at 696.3, 699.4, 707.5, and 713.9 eV. For KF, many spectral features at 686.8, 691.7, 693.5, 698.3, and $703.8 \mathrm{eV}$ can be observed. In contrast, the spectrum of $\mathrm{NH}_{4} \mathrm{~F}$ shows only little features at 690.0, 694.0, and $699.5 \mathrm{eV}$. Furthermore, the spectrum of $\mathrm{CaF}_{2}$ exhibits a sharp whiteline at $688.0 \mathrm{eV}$ and further features at 691.3, 694.7, 697.8, and 702.6 eV. For fluoroapatite (FAp), the data show a very similar whiteline

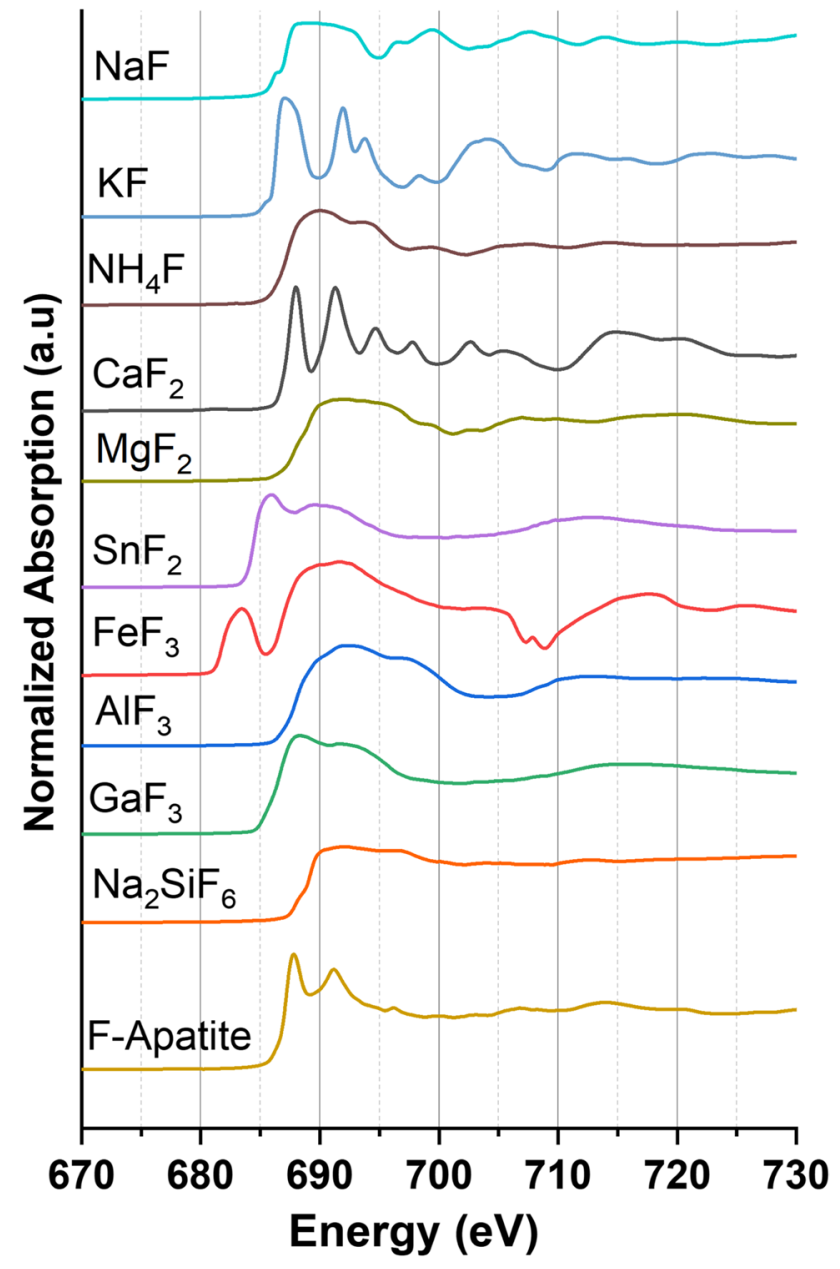

Fig. 1 Normalized fluorine K-edge XANES spectra of various inorganic fluorine compounds; fluoroapatite (F-Apatite)

at $687.8 \mathrm{eV}$ but only two additional spectral features at 691.1 and $696.2 \mathrm{eV}$. For $\mathrm{MgF}_{2}$, a broad whiteline at $691.5 \mathrm{eV}$ and two features at 706.6 and $720.5 \mathrm{eV}$ were recorded, which is in good agreement with previous measurements (Oizumi et al. 1985) In contrast, the spectrum of $\mathrm{FeF}_{3} \cdot 3 \mathrm{H}_{2} \mathrm{O}$ depicts a broad whiteline between 689.0 and $693.0 \mathrm{eV}$ and a large pre-peak at $683.3 \mathrm{eV}$ that was previously detected on other iron fluorides (Murugesan et al. 2019). In addition, interaction with the iron $(\mathrm{Fe}) \mathrm{L}$-edge is visible between 705 and $713 \mathrm{eV}$. The spectrum of $\mathrm{AlF}_{3} \cdot 3 \mathrm{H}_{2} \mathrm{O}$ shows only two major spectral features at 692.0 and $697.5 \mathrm{eV}$, while $\mathrm{Na}_{2} \mathrm{SiF}_{6}$ has a large whiteline with two maxima at 692 and $696.6 \mathrm{eV}$ and a little feature at $713.3 \mathrm{eV}$. Eventually, the spectra of $\mathrm{GaF}_{3}$ and $\mathrm{SnF}_{2}$ display only two broad features at 688.2 and 691.8 and 685.9 and $698.7 \mathrm{eV}$, respectively.

In summary, almost all recorded PFAS spectra show two very characteristic broad features at 688.5 and $692.0 \mathrm{eV}$, enabling a clear differentiation from inorganic fluorides (see Figs. 1 and 2). This is in good agreement with the 


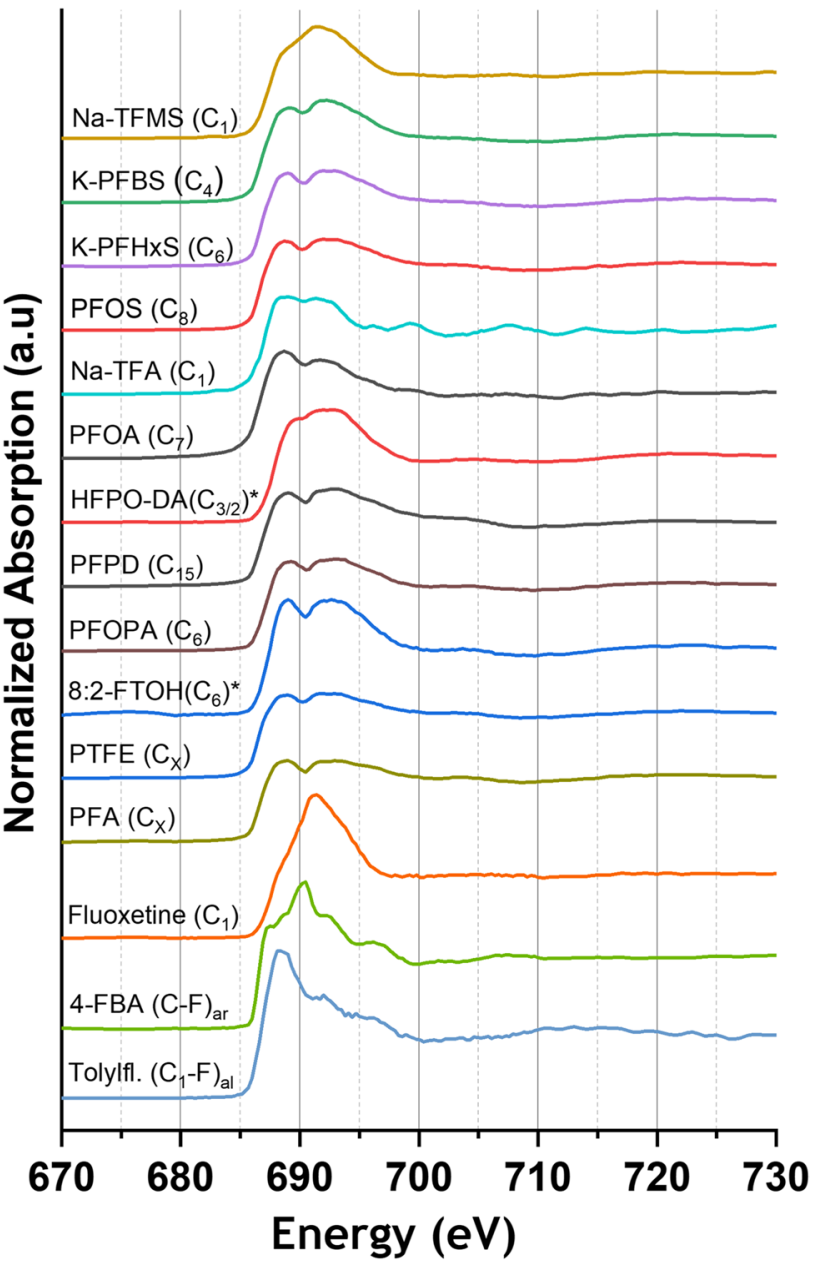

Fig. 2 Normalized fluorine K-edge XANES spectra of various fluorinated organic compounds; numbers in brackets show the number of the fully fluorinated carbon atoms per molecule; sodium trifluoromethyl sulfonate (Na-TFMS), potassium perfluorobutyl sulfonate (K-PFBS), potassium perfluorhexyl sulfonate (K-PFHxS), perfluorooctanesulfonic acid (PFOS), sodium trifluoroacetate (Na-TFA), perfluorooctanoic acid (PFOA), perfluoro-2-propoxypropanoic acid (HFPO-DA), perfluoropentadecane (PFPD), 1H,1H,2H,2H-perfluorooctanephosphonic acid (PFOPA), 8:2 fluorotelomer alcohol (8:2FTOH), polytetrafluorethylene (PTFE), perfluoroalkoxy alkanes polymer (PFA), 4-fluorobenzoic acid (4-FBA) - aromatic C-F bond, tolylfluanid (tolylff.) — aliphatic C-F bond; * embedded in fluorinefree polyacrylate adhesive

STXM-XANES spectra of PFOA of Yan and coworkers. Moreover, the featured transitions were assigned to $\mathrm{F}$ $1 \mathrm{~s} \rightarrow \sigma^{*} \mathrm{C}-\mathrm{F}$ transitions of $\mathrm{C}-\mathrm{F}$ bond in the $-\mathrm{CF}_{2}-\mathrm{CF}_{2}$ - chain (Yan et al. 2021). Most notably, this can be regarded in the F K-edge XANES spectrum of the fluoropolymers PTFE and PFA, showing also these specific spectral features. For HFPO-DA, the characteristic broad features are shifted to 689.2 and $692.4 \mathrm{eV}$. However, due to the high vapor pressure, HFPO-DA and 8:2-FTOH were embedded into polyacrylate adhesive which might explain the shift of the energy maxima. Furthermore, the spectrum of fluoxetine exhibits a

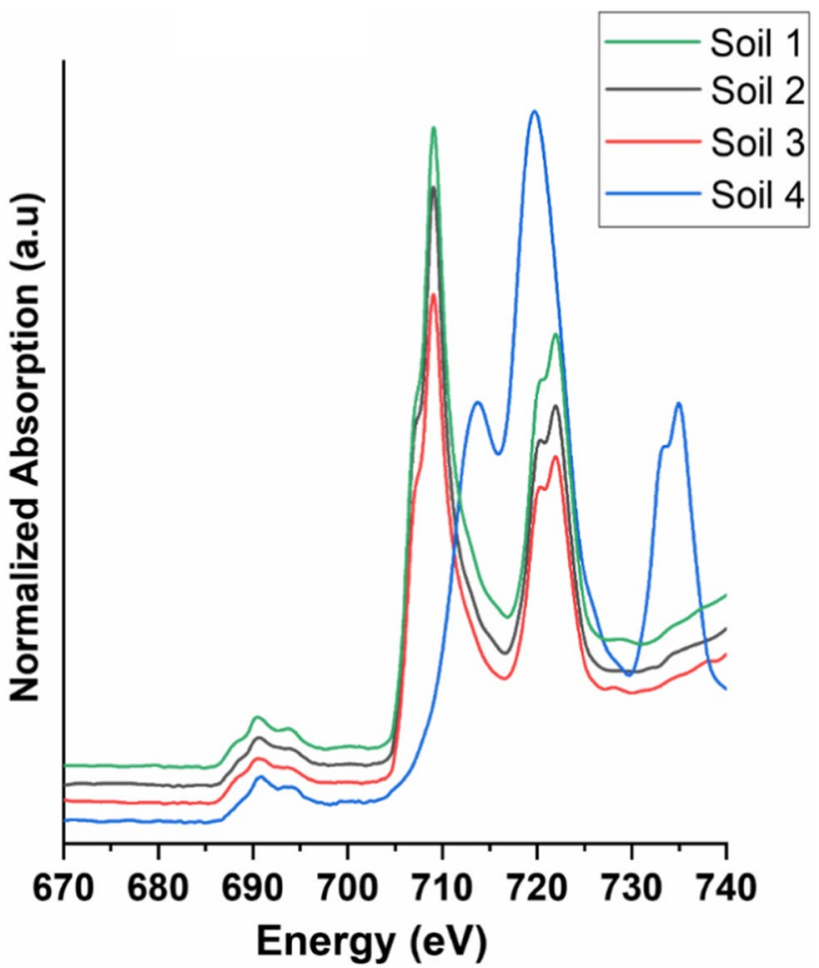

Fig. 3 Normalized fluorine K-edge and iron L-edge XANES spectra of the four investigated soil samples

very similar pattern compared to the spectrum of Na-TFMS since both compounds contain only one $\mathrm{CF}_{3}$ group. In contrast, the mono-fluorinated organic compounds tolylfluanid and 4-FBA show very different shapes of fluorine signals in their F K-edge XANES spectra with a maximum at $688.1 \mathrm{eV}$ $\left(\mathrm{C}-\mathrm{F}_{\mathrm{al}}\right)$ and $690.3 \mathrm{eV}\left(\mathrm{C}-\mathrm{F}_{\mathrm{ar}}\right)$, respectively.

In general, the spectral feature at $692.0 \mathrm{eV}$ has a higher intensity for (ultra-)short-chain perfluorosulfonic acids compared with long-chain perfluorosulfonic acids. Therefore, the spectral intensity ratio $688.5 \mathrm{eV} / 692.0 \mathrm{eV}$ is inversely proportional to the decreasing chain length of the perfluorosulfonic acid group. This might hold true for perfluorocarboxylic acids, since the ultrashort-chain TFA has a higher intensity at $692 \mathrm{eV}$ than the long-chain PFOA (see Fig. 2). Thus, the F K-edge XANES technique allows to differentiate between short- and long-chain PFAS within a given PFAS compound class.

\section{Investigation of PFAS-contaminated solid matrices by fluorine K-edge XANES spectroscopy}

Figure 3 shows the full F K-edge XANES spectra of the analyzed soils (1-4), displaying strong features between 705 to $740 \mathrm{eV}$ that can be attributed to absorption bands of the Fe L-edge. 
Usually, the intensity of an element-specific L-edge spectrum is much lower than for the K-edge, but soils naturally contain much more iron than fluorine compounds. Consequently, the higher intensities of Fe L-edge features lead to an overlap in the post-edge region of the F K-edge XANES spectra. Therefore, we focused on the range from 680 to $705 \mathrm{eV}$ in the F K-edge XANES spectra of the analyzed soils and sewage sludges (see Fig. 4).

All analyzed soil samples (Fig. 4 top) show three characteristic features in the F K-edge bulk-XANES spectrum at 688.0, 690.5, and 694.0 eV in different intensities. Besides small alternations between the samples, no characteristic differences could be identified in the respective XANES spectra. In contrast, the sewage sludge samples (Fig. 4 bottom) show completely different XANES spectra with two major features at 688.0 and $691.0 \mathrm{eV}$. However, the spectral features of the soils and sewage sludges could not be assigned to a specific fluorine compound.

To determine the "detection limit" of this method, we used an approach to analyze quartz spiked with PFOS of various concentrations $(1000,100,10,1$, and $0.1 \mathrm{mg} / \mathrm{kg} \mathrm{F}$;

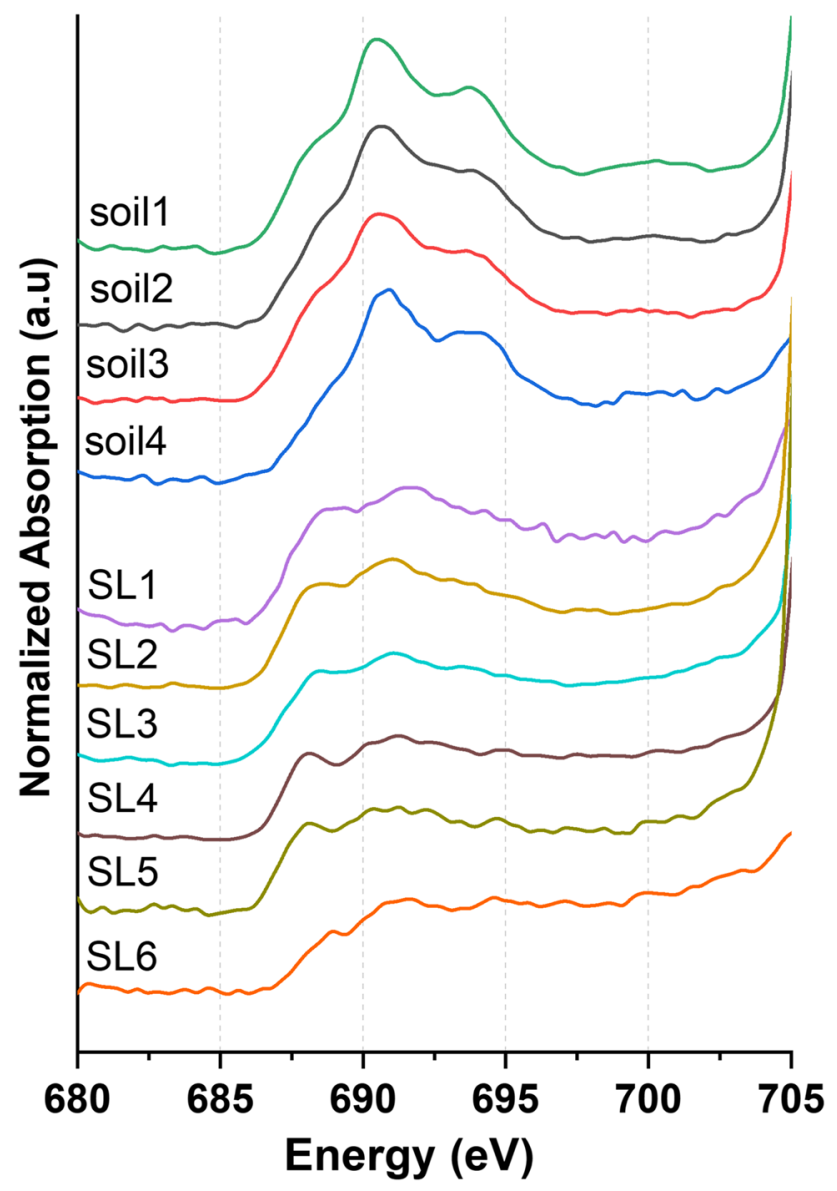

Fig. 4 Normalized fluorine K-edge bulk-XANES spectra of the investigated soils (soil1-4) and sewage sludges (SL1-6) see Fig. S1). With the collection of one single F K-edge XANES spectrum, 1000 and $100 \mathrm{mg} / \mathrm{kg}$ PFOS-fluorine in quartz showed a nice fluorine K-edge XANES spectrum. At concentration level $10 \mathrm{mg} / \mathrm{kg}$, the fluorine signal still shows the shape of the PFOS spectrum, but 1 and $0.1 \mathrm{mg} /$ kg PFOS-F could not be detected anymore. Please note that the quality of spectra with a high signal-to-noise ratio can be significantly improved upon addition of several scans of the same sample. Nevertheless, it must be kept in mind that choosing higher photon flux at the beamline and merging of many scans can also decrease the "detection limit" for XANES spectroscopy (Proux et al. 2017). Therefore, it is not straightforward to specify a general detection limit for this method.

\section{Linear combination analysis of PFAS in fluorine K-edge XANES spectra}

In order to analyze the fluorine composition of the samples in more detail, it is possible to perform linear combination (LC) fits of the bulk-XANES spectra based on the recorded spectral information of various inorganic and organic fluorine compounds (Calvin and Furst 2013). This software-based method assembles a library of standards and allows to sum them in various linear combinations, in order to approximate the experimental XANES spectral data as close as possible. LC fitting therefore is very effective to identify the relative number of known constituents that are present in the sample. The results of the performed LC fits are shown in Table 1. All LC fits are classified with the help of the goodness of fit $R$-factor. A lower $R$-factor indicates a better LC fit, whereas an $R$-factor $>0.1$ presumes that the model is fundamentally incorrect (Calvin and Furst 2013). $R$-values $<0.02$ can be interpreted as "good enough," while values between 0.02 and 0.10 indicate some major incorrection of the model.

For all soils as well as SL1 and SL2, the best LCF fit (Table 1) indicates a PFAS as major F compounds in the sample. Additionally, the fits indicate also minerals such as fluoroapatite $\left(\mathrm{Ca}_{5}\left(\mathrm{PO}_{4}\right)_{3} \mathrm{~F}\right)$ and fluorite $\left(\mathrm{CaF}_{2}\right)$, which belong to the major F-containing minerals in soils (Fuge and Andrews 1988). Due to the existence of only few inorganic fluorides that can occur in natural soils and sludges, the accuracy of the fits is expected to be higher, compared to those for organic PFAS. Some XANES spectra of structurally similar organofluorine compounds are similar, such as for PFOS and PFOPA. Thus, the LC fitting approach is limited in distinguishing between similar organic fluorinated compounds but shows a higher precision with inorganic fluorides. Moreover, some samples exhibit unrealistically large amounts of PFAS in the LC fits in relation to the total fluorine amount, such as for soil1. One representative sample for a high PFAS content in the LC fit is SL2, displayed in Fig. 5. 
Table 1 Summary of the best fits for the linear combination (LC) fittings of the bulk-XANES spectra and the corresponding goodness of fit factors $\left(R\right.$-factor and reduced $\left.\chi^{2}\right)$. A lower $R$-factor and reduced $\chi^{2}$ indicate a better fit

\begin{tabular}{|c|c|c|c|}
\hline Sample & Best LCF fit & $R$-factor & Reduced $\chi^{2}$ \\
\hline \multirow[t]{2}{*}{ Soil1 } & $98 \%$ fluoxetine $+2 \% \mathrm{Na}_{2} \mathrm{SiF}_{6}$ & 0.042 & 0.036 \\
\hline & $\begin{array}{l}71 \% \mathrm{MgF}_{2}+13 \% \mathrm{NaF} \\
\quad+16 \% \mathrm{CaF}_{2}\end{array}$ & 0.060 & 0.086 \\
\hline \multirow[t]{2}{*}{ Soil2 } & $\begin{array}{l}84 \% \text { fluoxetine }+13 \% \mathrm{Na}_{2} \mathrm{SiF}_{6} \\
\quad+3 \% \mathrm{MgF}_{2}\end{array}$ & 0.033 & 0.026 \\
\hline & $\begin{array}{l}65 \% \mathrm{MgF}_{2}+20 \% \mathrm{Na}_{2} \mathrm{SiF}_{6} \\
\quad+15 \% \text { FAp }\end{array}$ & 0.084 & 0.067 \\
\hline \multirow[t]{2}{*}{ Soil3 } & $80 \%$ fluoxetine $+20 \% \mathrm{Na}_{2} \mathrm{SiF}_{6}$ & 0.029 & 0.020 \\
\hline & $\begin{array}{l}56 \% \mathrm{MgF}_{2}+28 \% \text { FAp } \\
+16 \% \mathrm{Na}_{2} \mathrm{SiF}_{6}\end{array}$ & 0.072 & 0.049 \\
\hline \multirow[t]{2}{*}{ Soil4 } & $69 \%$ fluoxetine $+31 \% \mathrm{Na}_{2} \mathrm{SiF}_{6}$ & 0.172 & 0.108 \\
\hline & $\begin{array}{l}51 \% \mathrm{MgF}_{2}+38 \% \mathrm{Na}_{2} \mathrm{SiF}_{6} \\
\quad+11 \% \mathrm{CaF}_{2}\end{array}$ & 0.218 & 0.139 \\
\hline \multirow[t]{2}{*}{ SL1 } & $\begin{array}{l}48 \% \mathrm{Na}-\mathrm{TFMS}+28 \% \mathrm{FAp} \\
\quad+24 \% \mathrm{Na}_{2} \mathrm{SiF}_{6}\end{array}$ & 0.054 & 0.061 \\
\hline & $\begin{array}{l}50 \% \mathrm{FAp}+40 \% \mathrm{Na}_{2} \mathrm{SiF}_{6} \\
\quad+10 \% \mathrm{MgF}_{2}\end{array}$ & 0.064 & 0.049 \\
\hline \multirow[t]{2}{*}{ SL2 } & $\begin{array}{l}47 \% \mathrm{Na}-\mathrm{TFMS}+33 \% \text { FAp } \\
\quad+20 \% \mathrm{Na}_{2} \mathrm{SiF}_{6}\end{array}$ & 0.018 & 0.006 \\
\hline & $\begin{array}{l}54 \% \text { FAp }+35 \% \mathrm{Na}_{2} \mathrm{SiF}_{6} \\
\quad+11 \% \mathrm{MgF}_{2}\end{array}$ & 0.026 & 0.010 \\
\hline \multirow[t]{2}{*}{ SL3 } & $\begin{array}{l}49 \% \mathrm{Na}_{2} \mathrm{SiF}_{6}+27 \% \mathrm{FAp} \\
\quad+24 \% \mathrm{NaF}\end{array}$ & 0.029 & 0.009 \\
\hline & $\begin{array}{l}44 \% \mathrm{NaF}+35 \% \mathrm{Na}_{2} \mathrm{SiF}_{6} \\
\quad+21 \% \mathrm{Na}-\mathrm{TFMS}\end{array}$ & 0.031 & 0.010 \\
\hline \multirow[t]{2}{*}{ SL4 } & $\begin{array}{l}48 \% \mathrm{Na}_{2} \mathrm{SiF}_{6}+34 \% \mathrm{NaF} \\
\quad+18 \% \mathrm{CaF}_{2}\end{array}$ & 0.040 & 0.012 \\
\hline & $89 \% \mathrm{Na}_{2} \mathrm{SiF}_{6}+11 \%$ tolylfluanid & 0.104 & 0.031 \\
\hline \multirow[t]{2}{*}{ SL5 } & $\begin{array}{l}42 \% \mathrm{Na}_{2} \mathrm{SiF}_{6}+40 \% \mathrm{NaF} \\
\quad+18 \% \mathrm{CaF}_{2}\end{array}$ & 0.040 & 0.012 \\
\hline & $\begin{array}{l}42 \% \mathrm{NaF}+39 \% \mathrm{Na}_{2} \mathrm{SiF}_{6} \\
\quad+19 \% \text { PFOS }\end{array}$ & 0.048 & 0.015 \\
\hline \multirow[t]{2}{*}{ SL6 } & $92 \% \mathrm{Na}_{2} \mathrm{SiF}_{6}+8 \% \mathrm{NaF}$ & 0.144 & 0.044 \\
\hline & $99 \% \mathrm{Na}_{2} \mathrm{SiF}_{6}+1 \%$ PFOS & 0.147 & 0.046 \\
\hline
\end{tabular}

Both calculated LC fits of SL2 are in good approximation to the original spectrum, assigned by the low $R$-value (Calvin and Furst 2013). One fit indicates a 47\% Na-TFMS, 33\% fluoroapatite, and $20 \% \mathrm{Na}_{2} \mathrm{SiF}_{6}$ composition, whereas the other suggests a $54 \%$ fluoroapatite, $20 \% \mathrm{Na}_{2} \mathrm{SiF}_{6}$, and $11 \%$ $\mathrm{MgF}_{2}$ distribution. While the first approximation included at least one fluorinated organic compound, resulting in an $R$-value of 0.018 , the second fit was based exclusively on inorganic fluorides, yielding a slightly higher $R$-value (0.026). In order to approach the results of the most appropriate fits, we analyze the total amount of organic fluorine (PFAS) in relation to the total fluorine (TF) amount. Consequently, we used combustion ion chromatography (CIC) to determine the $\mathrm{TF}$ and the extractable organic fluorine (EOF) content of the investigated samples.

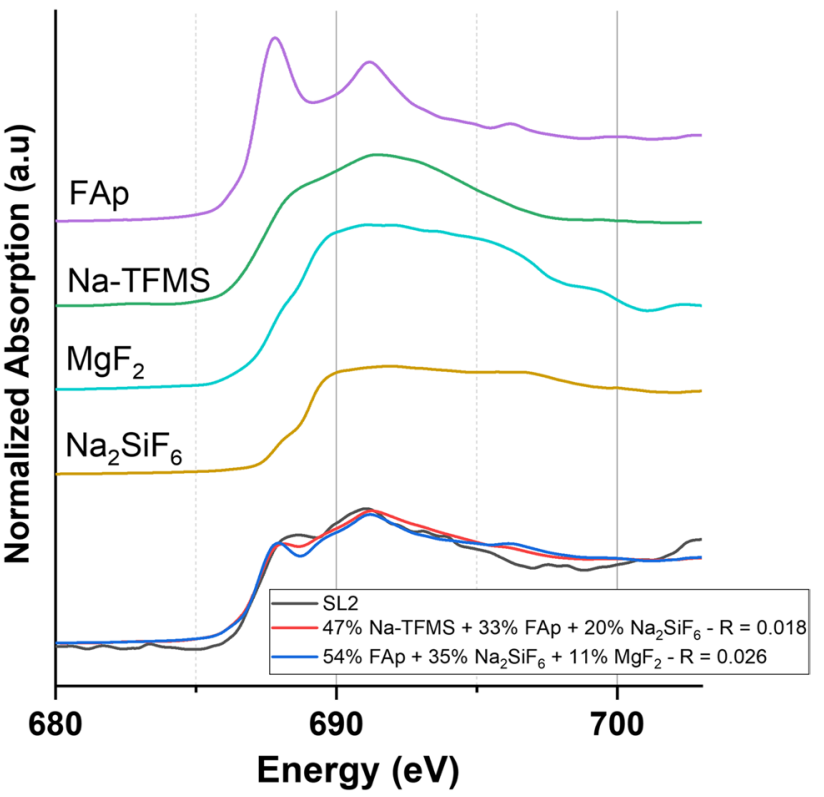

Fig. 5 Normalized fluorine K-edge XANES spectrum of SL2 and the best LC fits (bottom) with the applied reference fluorine compounds (top); fluoroapatite (FAp) and sodium trifluoromethyl sulfonate (NaTFMS)

\section{Total fluorine (TF) and extractable organic fluorine (EOF) analysis of PFAS-contaminated soils and sludges}

TF analysis of all samples was conducted by CIC. In order to improve the accuracy of the sum parameter $\mathrm{TF}, \mathrm{WO}_{3}$ was mixed as fluxing agent to the samples prior to investigation (Shimizu et al. 2015). We found this additive to yield comparable values to the significantly more toxic $\mathrm{V}_{2} \mathrm{O}_{5}$ highlighted in earlier studies on fluorine analysis of environmental samples (Wang et al. 2010). TF analysis was conducted for both, sewage sludge and soil samples, as displayed in Fig. 5 and Table S8.

The TF values of the sludge samples range between 23 and $513 \mathrm{mg} / \mathrm{kg}$ and for soils 156 and $1025 \mathrm{mg} / \mathrm{kg}$, most of which can be explained by the presence of inorganic fluorides and non-extractable organic fluorides. The occurrence of inorganic fluorides was also identified with the help of LC fitting of the recorded F XANES spectra (see Fig. 4). Fluoride levels for both matrices are in good agreement with literature data for comparable solid samples (Schuppli 1985; Codling et al. 2014; Geretharan et al. 2018).

Whereas several studies considering PFAS sum parameter analysis of contaminated soils were performed during the last decade (Wang et al. 2013; Codling et al. 2014; Tan et al. 2014; Lange et al. 2017), less attention was paid to PFAS sum parameter analysis of polluted sewage sludges (Yeung and Eriksson 2017; Aro et al. 2021). To determine the sum parameter EOF, all soil and sewage sludge samples (soil1-4, 
SL1-6) were extracted according to the modified process. In addition to the standard methanol elution step for the WAX cartridge, a second elution mainly for of the GCB phase was applied, using a combination of hexane and acetone. Utilizing various solvents for the SPE cartridges resulted in an unequal elution of the fluoro-organic compounds. The majority of the PFAS compounds showed a higher solubility and mobility in the significantly more polar $\mathrm{MeOH}$, compared to the significantly less polar hexane/acetone eluent (more details in table S9). Only samples SL1, SL4, as well as soil2 and soil3 yielded detectable fluoride values in their respective hexane/acetone fraction. This might be explained by the predominant presence of polar species in the total sample extracts. Figure 6 shows the cumulated EOF values for all studied samples in comparison with their respective TF values.

Comparatively high EOF values were detected for all sewage sludges samples, ranging from $155 \mu \mathrm{g} / \mathrm{kg}$ (SL2) up to $539 \mu \mathrm{g} / \mathrm{kg}$ (SL5) dry weight (dw). These values are in good conformance with EOF data reported by a recently conducted interlaboratory investigation of EOF sum parameter on sludge samples (Kärrman et al. 2021). Particularly high EOF values were detected for SL4, resulting in $7.21 \mathrm{mg}$ / $\mathrm{kg} \mathrm{dw}$. Measured EOF values were calculated between 0.04 and $1.84 \%$ of the total fluoride amount. Overall, the detected EOF levels clearly exceed the sum of values detected by target analytical methods in previous studies on different sewage sludge samples (Yoo et al. 2009; Gómez-Canela et al. 2012; Gallen et al. 2016; Eriksson et al. 2017; Bolan et al. 2021).

In comparison to sludge samples, soil samples soil2-4 originate from known PFAS-contaminated sites. Hence, EOF values for soil2-4 exhibit expectedly high concentrations of 48,941 , and $6985 \mu \mathrm{g} / \mathrm{kg} \mathrm{dw}$, respectively. Their respective EOF/TF percentages vary between 0.01 and $1.75 \%$ and are in good agreement with other reported EOF/ TF mass balances of contaminated soil (Tan et al. 2014) or water samples (Gehrenkemper et al. 2021; Koch et al. 2021). In contrast, soil1 is a known PFAS-free soil, yielding an EOF value below the LOQ.

\section{Conclusion}

In summary, we could show that fluorine K-edge XANES spectroscopy can be utilized to detect PFAS in high sample concentrations. The peak intensity ratio $688.5 \mathrm{eV} / 692.0 \mathrm{eV}$ in the PFAS XANES spectrum can be inversely correlated to the chain length of the perfluorosulfonic acid group and might be also applicable for perfluorocarboxylic acids. However, in environmental soil and sewage sludge samples, the presence of highly concentrated inorganic fluorides significantly decreases the spectral resolution. Linear
Fig. 6 Cumulated EOF values (combined hexanes/acetone and $\mathrm{MeOH}$ extraction) over $\mathrm{TF}$ values (blue) and respective EOF/TF percentages of the investigated sewage sludge and soil samples (note the log scale). The detected EOF value of soil1 was below the LOQ. All error bars correspond to the respective standard deviations $(n=3)$

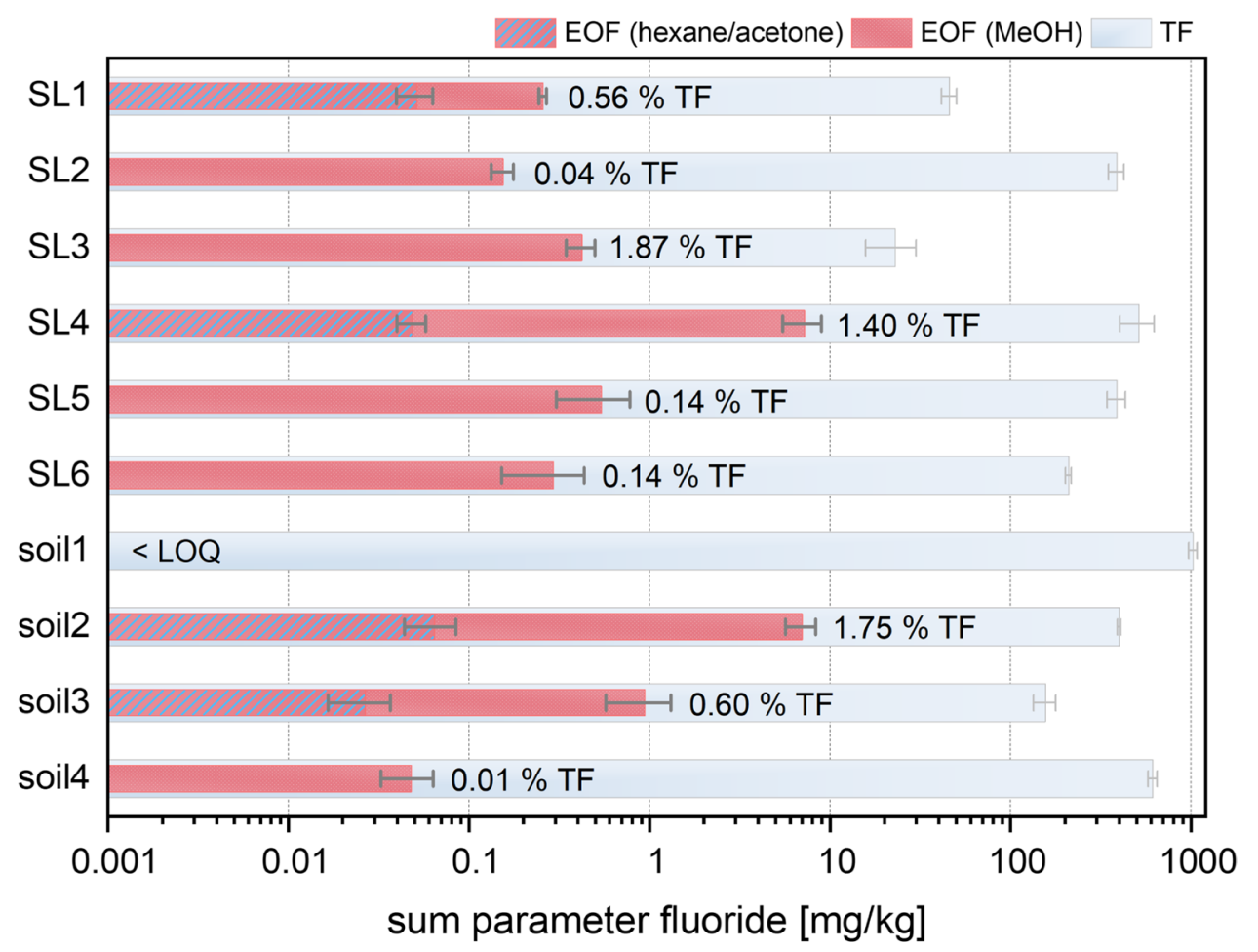


combination fitting was applied to predict fluorine species in the samples but could not be utilized for identification of specific PFAS. Nonetheless, fluorine K-edge XANES spectroscopy might be considered as an investigative tool in the qualitative analysis of high PFAS concentrations in environmental samples or can be utilized in the analysis of non-inorganic fluoride-containing materials. Compared to other surface detection methods like XPS, fluorine K-edge XANES spectroscopy allows for analysis of much lower concentrated samples, differentiation of inorganic and organic compounds, as well as greater matrix variety, such as soils, sludges, or PFAS-containing consumer products. Moreover, the technique might be suitable for in situ analysis of PFAS degradative processes, like chemically or physically induced PFAS degradation to short-chain compounds or evaluation of PFAS mineralization products. Additionally, the spectroscopic studies were complemented by quantitative sum parameter analysis, yielding a comprehensive picture of the PFAS contamination per sample. Since the detected EOF values were significantly higher than reported in previous target analytical-based studies, the contribution of sum parameter analysis can be considered beneficial.

Supplementary Information The online version contains supplementary material available at https://doi.org/10.1007/s11356-021-17838-z.

Acknowledgements We gratefully acknowledge the collaborative work with R. Sigle, K. Schumacher, and T. Eggloffstein (ICP-ING $\mathrm{mbH}$ ) concerning soil samples. Furthermore, we thank our BAM colleagues H. Herzel, T. Sichler, and C. Adam for providing sewage sludge samples.

Author contribution CV and PR: Conceptualization. CV, PR, PW, and TH: Formal analysis and methodology. FS and TH: Contributed to the data analysis. CV and PR: Original draft and writing. FS, PW, and TH: Review.

Funding Open Access funding enabled and organized by Projekt DEAL. The authors thank the German Federal Ministry of Economic Affairs and Energy (BMWi; ZIM program 16KN076702 "PerFluSanPFTSan" and 16KN076724 "MIDRAPA") for funding. Furthermore, we acknowledge the Paul Scherrer Institute, Villigen, Switzerland, for the provision of synchrotron radiation beamtime at PHOENIX beamline of the Swiss Light Source.

Data availability The datasets used and/or analyzed during the current study are available from the corresponding author on reasonable request.

\section{Declarations}

Ethics approval and consent to participate Not applicable.

Consent for publication Not applicable.

Competing interests The authors declare no competing interests.
Open Access This article is licensed under a Creative Commons Attribution 4.0 International License, which permits use, sharing, adaptation, distribution and reproduction in any medium or format, as long as you give appropriate credit to the original author(s) and the source, provide a link to the Creative Commons licence, and indicate if changes were made. The images or other third party material in this article are included in the article's Creative Commons licence, unless indicated otherwise in a credit line to the material. If material is not included in the article's Creative Commons licence and your intended use is not permitted by statutory regulation or exceeds the permitted use, you will need to obtain permission directly from the copyright holder. To view a copy of this licence, visit http://creativecommons.org/licenses/by/4.0/.

\section{References}

Aro R, Eriksson U, Kärrman A et al (2021) Fluorine mass balance analysis of effluent and sludge from Nordic countries. ACS ES\&T Water. https://doi.org/10.1021/acsestwater.1c00168

Ateia M, Maroli A, Tharayil N et al (2019) The overlooked short- and ultrashort-chain poly- and perfluorinated substances: a review. Chemosphere 220:866-882. https://doi.org/10.1016/j.chemo sphere.2018.12.186

Baduel C, Paxman CJ, Mueller JF (2015) Perfluoroalkyl substances in a firefighting training ground (FTG), distribution and potential future release. J Hazard Mater 296:46-53. https://doi.org/10. 1016/j.jhazmat.2015.03.007

Bolan N, Sarkar B, Vithanage M et al (2021) Distribution, behaviour, bioavailability and remediation of poly- and per-fluoroalkyl substances (PFAS) in solid biowastes and biowaste-treated soil. Environ Int 155:106600. https://doi.org/10.1016/j.envint.2021.106600

Calvin S, Furst KE (2013) XAFS for everyone

Codling G, Vogt A, Jones PD et al (2014) Historical trends of inorganic and organic fluorine in sediments of Lake Michigan. Chemosphere 114:203-209. https://doi.org/10.1016/j.chemosphere.2014.03.080

De Silva AO, Armitage JM, Bruton TA et al (2021) PFAS exposure pathways for humans and wildlife: a synthesis of current knowledge and key gaps in understanding. Environ Toxicol Chem 403:631-657. https://doi.org/10.1002/etc.4935

Eriksson U, Haglund P, Kärrman A (2017) Contribution of precursor compounds to the release of per- and polyfluoroalkyl substances (PFASs) from waste water treatment plants (WWTPs). J Environ Sci 61:80-90. https://doi.org/10.1016/j.jes.2017.05.004

Fuge R, Andrews MJ (1988) Fluorine in the UK environment. Environ Geochem Health 103:96-104. https://doi.org/10.1007/BF017 58677

Gallen C, Drage D, Kaserzon S et al (2016) Occurrence and distribution of brominated flame retardants and perfluoroalkyl substances in Australian landfill leachate and biosolids. J Hazard Mater 312:55-64. https://doi.org/10.1016/j.jhazmat.2016.03.031

Gehrenkemper L, Simon F, Roesch P et al (2021) Determination of organically bound fluorine sum parameters in river water samples-comparison of combustion ion chromatography (CIC) and high resolution-continuum source-graphite furnace molecular absorption spectrometry (HR-CS-GFMAS). Anal Bioanal Chem 4131:103-115. https://doi.org/10.1007/s00216-020-03010-y

Geretharan T, Jeyakumar P, Bretherton M et al (2018) Defining a standard method to measure the total and bioavailable concentration of fluorine in New Zealand soils. Microchem J 142:94-101. https:// doi.org/10.1016/j.microc.2018.06.018

Giesy JP, Kannan K (2001) Global distribution of perfluorooctane sulfonate in wildlife. Environ Sci Technol 357:1339-1342. https:// doi.org/10.1021/es001834k 
Glüge J, Scheringer M, Cousins IT et al (2020) An overview of the uses of per- and polyfluoroalkyl substances (PFAS). Environ Sci Processes Impacts. https://doi.org/10.1039/D0EM00291G

Gómez-Canela C, Barth JAC, Lacorte S (2012) Occurrence and fate of perfluorinated compounds in sewage sludge from Spain and Germany. Environ Sci Pollut Res 199:4109-4119. https://doi.org/ 10.1007/s11356-012-1078-7

Gross KA, Hart JN, Rodríguez-Lorenzo LM (2001) Fluor-hydroxyapatite solid solutions as alternative bioceramics. Key Eng Mater 218-220:165-170. https://doi.org/10.4028/www.scientific.net/ KEM.218-220.165

Hill PJ, Taylor M, Goswami P et al (2017) Substitution of PFAS chemistry in outdoor apparel and the impact on repellency performance. Chemosphere 181:500-507. https://doi.org/10.1016/j. chemosphere.2017.04.122

Houtz EF, Sedlak DL (2012) Oxidative conversion as a means of detecting precursors to perfluoroalkyl acids in urban runoff. Environ Sci Technol 4617:9342-9349. https://doi.org/10.1021/ es302274g

Hudson E, Moler E, Zheng Y et al (1994) Near-edge sodium and fluorine K-shell photoabsorption of alkali halides. Phys Rev B 496:3701-3708. https://doi.org/10.1103/PhysRevB.49.3701

Jacob P, Barzen-Hanson KA, Helbling DE (2021) Target and nontarget analysis of per- and polyfluoralkyl substances in wastewater from electronics fabrication facilities. Environ Sci Technol. https://doi. org/10.1021/acs.est.0c06690

Janda J, Nödler K, Scheurer M et al (2019) Closing the gap - inclusion of ultrashort-chain perfluoroalkyl carboxylic acids in the total oxidizable precursor (TOP) assay protocol. Environ Sci Processes Impacts 2111:1926-1935. https://doi.org/10.1039/C9EM00169G

Kärrman A, Elgh-Dalgren K, Lafossas C et al (2011) Environmental levels and distribution of structural isomers of perfluoroalkyl acids after aqueous fire-fighting foam (AFFF) contamination. Environ Chem 84:372-380. https://doi.org/10.1071/EN10145

Kärrman A, Yeung L, Spaan KM et al (2021) Can determination of extractable organofluorine (EOF) be standardized? First interlaboratory comparisons of EOF and fluorine mass balance in sludge and water matrices. Environ Sci Processes Impacts. https://doi. org/10.1039/D1EM00224D

Kissa E (2001) Fluorinated surfactants and repellents, 2nd edn. Taylor \& Francis

Koch A, Kärrman A, Yeung LWY et al (2019) Point source characterization of per- and polyfluoroalkyl substances (PFASs) and extractable organofluorine (EOF) in freshwater and aquatic invertebrates. Environ Sci Processes Impacts 2111:1887-1898. https://doi.org/ 10.1039/C9EM00281B

Koch A, Aro R, Wang T et al (2020) Towards a comprehensive analytical workflow for the chemical characterisation of organofluorine in consumer products and environmental samples. Trends Anal Chem 123:115423. https://doi.org/10.1016/j.trac.2019.02.024

Koch A, Yukioka S, Tanaka S et al (2021) Characterization of an AFFF impacted freshwater environment using total fluorine, extractable organofluorine and suspect per- and polyfluoroalkyl substance screening analysis. Chemosphere 276:130179. https://doi.org/ 10.1016/j.chemosphere.2021.130179

Kotthoff M, Fliedner A, Rüdel H et al (2020) Per- and polyfluoroalkyl substances in the German environment - levels and patterns in different matrices. Sci Total Environ 740:140116. https://doi.org/ 10.1016/j.scitotenv.2020.140116

Lallas PL (2017) The Stockholm convention on persistent organic pollutants. Am J Int Law 953:692-708. https://doi.org/10.2307/ 2668517

Lange FT, Körner B, Müller J (2017) Entwicklung eines fluorspezifischen Gruppenparameters EOF für Boden und weitere Feststoffmatrices, DVGW-Technologiezentrum Wasser (TZW): 58
Leeson A, Thompson T, Stroo HF et al (2021) Identifying and managing aqueous film-forming foam (AFFF)-derived PFAS in the environment. Environ Toxicol Chem 401:24-36. https://doi.org/ 10.1002/etc. 4894

Lindstrom AB, Strynar MJ, Libelo EL (2011) Polyfluorinated compounds: past, present, and future. Environ Sci Technol 4519:7954 7961. https://doi.org/10.1021/es2011622

Liu J, Mejia Avendano S (2013) Microbial degradation of polyfluoroalkyl chemicals in the environment: a review. Environ Int 61:98114. https://doi.org/10.1016/j.envint.2013.08.022

Miyake Y, Yamashita N, Rostkowski P et al (2007) Determination of trace levels of total fluorine in water using combustion ion chromatography for fluorine: a mass balance approach to determine individual perfluorinated chemicals in water. J Chromatogr A 11431:98-104. https://doi.org/10.1016/j.chroma.2006.12.071

Mumtaz M, Bao Y, Liu L et al (2019) Per- and polyfluoroalkyl substances in representative fluorocarbon surfactants used in Chinese film-forming foams: levels, profile shift, and environmental implications. Environ Sci Technol Lett 65:259-264. https://doi.org/10. 1021/acs.estlett.9b00154

Murugesan V, Cho JS, Govind N et al (2019) Lithium insertion mechanism in iron fluoride nanoparticles prepared by catalytic decomposition of fluoropolymer. ACS Appl Energy Mater 23:1832-1843. https://doi.org/10.1021/acsaem.8b01983

Nakai S-I, Ohashi M, Mitsuishi T et al (1986) F-K XANES studies of alkali fluorides. J Phys Soc Jpn 557:2436-2442. https://doi.org/ 10.1143/JPSJ.55.2436

Nakayama SF, Yoshikane M, Onoda Y et al (2019) Worldwide trends in tracing poly- and perfluoroalkyl substances (PFAS) in the environment. Trends Anal Chem 121:115410. https://doi.org/10.1016/j. trac.2019.02.011

Nickerson A, Maizel AC, Kulkarni PR et al (2020) Enhanced extraction of AFFF-associated PFASs from source zone soils. Environ Sci Technol 548:4952-4962. https://doi.org/10.1021/acs.est.0c00792

OECD (2018) Toward a new comprehensive global database of perand polyfluoroalkyl substances (PFASs): summary report on updating the OECD 2007 list of per- and polyfluoroalkyl substances (PFASs). Series on Risk Management No. 39

Oizumi H, Fujikawa T, Ohashi M et al (1985) F-K XANES studies of alkaline-earth fluorides. J Phys Soc Jpn 5410:4027-4033. https:// doi.org/10.1143/JPSJ.54.4027

Proux O, Lahera E, Del Net W, Kieffer I, Rovezzi M, Testemale D, Irar M, Thomas S, Aguilar-Tapia A, Bazarkina EF, Prat A, Tella M, Auffan M, Rose J, Hazemann J-L (2017) High-energy resolution fluorescence detected X-ray absorption spectroscopy: a powerful new structural tool in environmental biogeochemistry sciences. J Environ Qual 46(6):1146-1157. https://doi.org/10.2134/jeq20 17.01 .0023

Ravel B, Newville M (2005) ATHENA, ARTEMIS, HEPHAESTUS: data analysis for X-ray absorption spectroscopy using IFEFFIT. J Synchrotron Radiat 12(Pt 4):537-541. https://doi.org/10.1107/ S0909049505012719

Roesch P, Vogel C, Simon F-G (2020) Reductive defluorination and mechanochemical decomposition of per- and polyfluoroalkyl substances (PFASs): from present knowledge to future remediation concepts. Int J Environ Res Public Health 1719:7242. https://doi. org/10.3390/ijerph17197242

Schaider LA, Balan SA, Blum A et al (2017) Fluorinated compounds in U.S. fast food packaging. Environ Sci Technol Lett 43:105-111. https://doi.org/10.1021/acs.estlett.6b00435

Schellenberger S, Jönsson C, Mellin P et al (2019) Release of sidechain fluorinated polymer-containing microplastic fibers from functional textiles during washing and first estimates of perfluoroalkyl acid emissions. Environ Sci Technol 5324:14329-14338. https://doi.org/10.1021/acs.est.9b04165 
Schroeder SLM, Weiher N (2006) F K-edge X-ray absorption nearedge structure (XANES) of AlF3 polymorphs: combining ab initio calculations with Walsh correlation diagrams. Phys Chem Chem Phys 815:1807-1811. https://doi.org/10.1039/B518124K

Schultes L, Vestergren R, Volkova K et al (2018) Per- and polyfluoroalkyl substances and fluorine mass balance in cosmetic products from the Swedish market: implications for environmental emissions and human exposure. Environ Sci Processes Impacts 2012:1680-1690. https://doi.org/10.1039/C8EM00368H

Schultes L, Peaslee GF, Brockman JD et al (2019) Total fluorine measurements in food packaging: how do current methods perform? Environ Sci Technol Lett 62:73-78. https://doi.org/10.1021/acs. estlett.8b00700

Schuppli PA (1985) Total fluorine in Cssc reference soil samples. Can J Soil Sci 653:605-607. https://doi.org/10.4141/cjss85-065

Shimizu K, Suzuki K, Saitoh M et al (2015) Simultaneous determinations of fluorine, chlorine, and sulfur in rock samples by ion chromatography combined with pyrohydrolysis. Geochem J 491:113-124. https://doi.org/10.2343/geochemj.2.0338

Spaan KM, van Noordenburg C, Plassmann MM et al (2020) Fluorine mass balance and suspect screening in marine mammals from the northern hemisphere. Environ Sci Technol 547:4046-4058. https://doi.org/10.1021/acs.est.9b06773

Stoiber T, Evans S, Naidenko OV (2020) Disposal of products and materials containing per- and polyfluoroalkyl substances (PFAS): a cyclical problem. Chemosphere 260:127659. https://doi.org/10. 1016/j.chemosphere.2020.127659

Sun M, Arevalo E, Strynar M et al (2016) Legacy and emerging perfluoroalkyl substances are important drinking water contaminants in the Cape Fear River watershed of North Carolina. Environ Sci Technol Lett 312:415-419. https://doi.org/10.1021/acs.estlett. $6 \mathrm{~b} 00398$

Sunderland EM, Hu XC, Dassuncao C et al (2019) A review of the pathways of human exposure to poly- and perfluoroalkyl substances (PFASs) and present understanding of health effects. $\mathbf{J}$ Expo Sci Environ Epidemiol 292:131-147. https://doi.org/10. 1038/s41370-018-0094-1

Tan B, Wang T, Wang P et al (2014) Perfluoroalkyl substances in soils around the Nepali Koshi River: levels, distribution, and mass balance. Environ Sci Pollut Res 2115:9201-9211. https://doi.org/10. 1007/s11356-014-2835-6

Tokranov AK, Nishizawa N, Amadei CA et al (2019) How do we measure poly- and perfluoroalkyl substances (PFASs) at the surface of consumer products? Environ Sci Technol Lett 61:38-43. https:// doi.org/10.1021/acs.estlett.8b00600

Vogel C, Krueger O, Herzel H et al (2016) Chemical state of mercury and selenium in sewage sludge ash based P-fertilizers. J Hazard Mater 313:179-184. https://doi.org/10.1016/j.jhazmat.2016.03.079

von Abercron E, Falk S, Stahl T et al (2019) Determination of adsorbable organically bound fluorine (AOF) and adsorbable organically bound halogens as sum parameters in aqueous environmental samples using combustion ion chromatography (CIC). Sci Total Environ 673:384-391. https://doi.org/10.1016/j.scitotenv.2019.04.068

Wagner A, Raue B, Brauch H-J et al (2013) Determination of adsorbable organic fluorine from aqueous environmental samples by adsorption to polystyrene-divinylbenzene based activated carbon and combustion ion chromatography. J Chromatogr A 1295:8289. https://doi.org/10.1016/j.chroma.2013.04.051

Wang Q, Makishima A, Nakamura E (2010) Determination of fluorine and chlorine by pyrohydrolysis and ion chromatography: comparison with alkaline fusion digestion and ion chromatography. Geostand Geoanal Res 342:175-183. https://doi.org/10.1111/j. 1751-908X.2010.00043.x

Wang P, Wang T, Giesy JP et al (2013) Perfluorinated compounds in soils from Liaodong Bay with concentrated fluorine industry parks in China. Chemosphere 916:751-757. https://doi.org/10.1016/j. chemosphere.2013.02.017

Wang W, Rhodes G, Ge J et al (2020) Uptake and accumulation of per- and polyfluoroalkyl substances in plants. Chemosphere 261:127584. https://doi.org/10.1016/j.chemosphere.2020.127584

Wilhelm S, Lorenz C, Muschket M et al (2019) Optimierung der EOF-Analytik unter Berücksichtigung der Beiträge verschiedener Stoffklassen poly- und perfluorierter Verbindungen, FraunhoferGesellschaft zur Förderung der angewandten Forschung e.V.; Landwirtschaftliches Technologiezentrum Augustenberg (LTZ); Helmholtz-Zentrum für Umweltforschung GmbH - UFZ; Universität Tübingen; Technologiezentrum Wasser (TZW): 144

Willach S, Brauch H-J, Lange FT (2016) Contribution of selected perfluoroalkyl and polyfluoroalkyl substances to the adsorbable organically bound fluorine in German rivers and in a highly contaminated groundwater. Chemosphere 145:342-350. https://doi. org/10.1016/j.chemosphere.2015.11.113

Yan B, Wang J, Liu J (2021) STXM-XANES and computational investigations of adsorption of per- and polyfluoroalkyl substances on modified clay. Water Res 201:117371. https://doi.org/10.1016/j. watres.2021.117371

Yeung LW, De Silva AO, Loi EI et al (2013) Perfluoroalkyl substances and extractable organic fluorine in surface sediments and cores from Lake Ontario. Environ Int 59:389-397. https://doi.org/10. 1016/j.envint.2013.06.026

Yeung LWY, Eriksson U (2017) Time trend of unidentified poly- and perfluoroalky alkyl substances in sludge from wastewater treatment plants in Sweden, Naturvårdsverket: 52

Yoo H, Washington JW, Jenkins TM et al (2009) Analysis of perfluorinated chemicals in sludge: method development and initial results. J Chromatogr A 121645:7831-7839. https://doi.org/10.1016/j. chroma.2009.09.051

Publisher's note Springer Nature remains neutral with regard to jurisdictional claims in published maps and institutional affiliations. 